\title{
SEGREDO PROFISSIONAL
}

III

Feliz acaso deparou-nos a leitura de um estudo do snr. dr. Firmino Lopes de Castro inserto na «Revista Medico-Legal» de I. de Junho de i 896, que é dada a lume pela Sociedade de Medicina Legal da Bahia. Nesse trabalho scientifico faz-se referencia e breve reparo critico ao estudo que, sobre o segredo profissional, tivemos a honra de estampar no terceiro volume da Revista desta Faculdade de Direito.

Resolvemos, pois, oppor contestação ao referido reparo critico, já para melhor elucidação do assumpto e já por merecida deferencia ao nosso douto contradictor.

Consoante á doutrina de Faustin e Hélie e em contrario ao modo de vêr de Enrico Pessina e ao nosso, opina o illustrado redactor da «Revista MedicoLegal» que o assentimento expresso e válido das pessoas interessadas na inviolabilidade do segredo profissional não desveste de criminalidade, ante a lei criminal brasileira, o desvendamento do mesmo segredo. 


\section{$-170-$}

Os fundamentos desta opinião expressou-os o critico no seguinte trecho: «desde que não é material«mente impossivel a criminação do desvendamento, «quando consentida pelo respectivo interessado, mui «ao envez do que pretende o douto lente da acade«mia paulista, para que se podesse ter como certa «aquella impunibilidade ante a lei penal brazileira, «fôra mistér que esta o declarasse por preceito ex«presso, ou fizesse explicitamente depender a figura «delictuosa dạ violação do sigillo, da circumstancia «de ter sido o desvendamento deste practicado sem «autorisação daquelle a quem elle pertence, como pre«cisamente procedeu o Codigo do Imperio allemão, «a que, aliás, se refere o distincto professor. Ora, «desde que assim não se houve o legislador criminal "patrio, o que d'ahi se póde e deve concluir é que «foi sua mente tornar punivel a revelação do segredo; «ainda que precedida e determinada por aquella auto«risação. A identica conclusão chega A. Hallays, em «referencia ao Codigo francez, cujo art. 378, relativo «ao segुredo profissional, é, nesse particular, inteira«mente similhante ao art. I92 do Codigo brasileiro. «Realmente, pondo em relevo a ausencia, naquelle «artigo, da formula «sem autorisação», adoptada pelo «Codigo allemão; salientada a falta, no mesmo artigo, «de qualquer referencia a consentimento outorgado «ou denegado, o citado escriptor firma, sem hesitação, «deante da lei penal de seu paiz, o principio da pu«nibilidade da revelação, na propria hypothese de ha«ver o interessado eximido o profissional do dever do «sigillo. (André Hallays, Le Secret profissionel. pag. "4I). E, o que mais é, tal doutrina tem por si a «sancção dos tribunaes francezes, que hão, mais de «uma vez, decidido que subsiste a obrigação do se"gredo, ainda quando aquelle a quem os factos res«peitam e os confiou, requer-lhe a revelação. ('Decisão 
«da Cour royal de Montpellier, em 24 de Setembro "de 182I, da de Grenoble, em 23 de Agosto de «I 828 e da Cour de Cassation-caso Chabaudy, em "4 de Maio de I884. Vide Chauv. e HÉlre, Théor. «du Code pen. Bruxelles, i 844, vcl. III, pag. 3 I 8 e «André Hallays, op cit. pag. 34-35.»

Assim, os fundamentos da impugnação se reduzem a tres: a) não ser physica ou materialmente impossivel o delicto no caso figurado, porque, disse-o poucas linhas antes o douto critico, «não póde o «simples arbitrio da pessoa a quem pertence o se"gredo, fazer com que deixe elle`de existir, perdendo «o seu caracter proprio, que é determirado pela even«tualidade de prejuizos, de qualquer natureza, resul«tantes da respectiva violação»; b) não conter expressamente a lei penal brasileira a mesma restricção que se contém na letra do Codigo do Imperio allemão; c) ter por si o critico a autoridade de alguns julgados dos tribunaes francezes, dado o parallelismo da lei franceza e da nossa.

Examinemos o valor desses fundamentos.

Desde que não é contestavel em these, nem se contesta em hypothese, a admissibilidade da interpretação chamada restrictiva-aquella que dá a conhecer menos idéas do que as que os vocabulos parecem exprimir - temos por ocioso rebater o argumento deduzido da ausencia de expressa exclusão do acto pela lei brasileira, em confronto com a exclusão expressa feita pela lei alleman.

A exclusão expressa na nossa lei derimiria a possibilidade da controversia, a qual, portanto, só póde versar sobre a existencia de uma exclusão implicitá ou virtual, apoiada sobre a solida base de bem deduzida interpretação restrictiva. 
Ora, a restricção, tendente a desvendar a mente do legislador ou o sentido da lei, póde resultar da significação propria dos vocabulos, como ensina o profundo Mailher de Chassat, adduzindo para exemplo o vocabulo consentimento, que por si só exclue o êrro, a violencia e o dolo. (I) Foi á luz desta regra de hermeneutica que tivemos como excluido da figura juridica do art. I 92 do Cod. Penal o desvendamento do sigillo sendo precedido de devida autorisação; porque, escrevemos nós, "segredo divulgavel por autori«sação de quem o confia deixa de ser segredo, des«apparecendo, portanto, um dos elementos constituti«vos do crime, que é a natureza secreta do facto «revelado» (2).

Em contrario a este assérto, pensa o douto critico que ha cousas por sua natureza secretas ou não divulgaveis, porque sua revelação importa sempre a eventualidade de um prejuizo, e cousas que podem, indifferentemente, ser entregues ou subtraídas ao dominio da publicidade. E para mais accentuar o caracter absoluto de que reveste o segredo, invoca e cita o douto critico a autoridade dos lexicos que definem o segredo como sendo aquillo que não deve ser revelado, o que não convém seja dito a pessoa alguma.

O certo é, porém, que a idéa de segredo não tem o caracter absoluto que se lhe quer emprestar. Ella é toda relativa, não se podendo a prion determinar aquellas cousas cuja divulgação póde ser nociva e que, por tal motivo, devem ficar sob sigillo. Mutavel como a face dos acontecimentos, ou como os interesses varios de cada dia e até de cada hora, a eventualidade de prejuizos não póde constituir um

(I) Mailher de Chassat. Traité de L'Interpret. des Lois-Paris, I822, § I27, pag. 204.

(2) Rev. da Fac. de Dir. de S. Paulo, vol. III. pag. зо. 
caracter objectivo, fixo e inseparavel de certas e determinadas cousas, de modo a imprimir-lhes o sello de não revelaveis ou absolutamente confidenciaes. A revelação que hoje acarretaria seguro e temivel damno, poderá amanhan proporcionar vantagem certa e ardentemente ambicionada; o mysterio em que se envolve o conspirador para furtar-se ao peso da sancção legal, volve-se logo em glorioso nimbo, no dia em que um lance da fortuna e um rasgo de audacia mudam o scenario politico. Ninguem, certamente, tem interesse em passar por invalido e em ser tido na conta de imbecil, mas a historia registra que Bruto afivelou ao rosto, para fins politicos, a mascara da imbecilidade, e que Sixto $V$, por ambicionar a thiára, por largo tempo carregou mulêtas e apparentou achaques que não soffria.

$\mathrm{Si}$ o sígillo professional só é resguardado pelas leis criminaes em attenção aos prejuizos que sóe e póde acarretar a divulgação de certos factos; si o prejuizo é todo relativo, dependente de mil circumstancias, muitas vezes fóra de todas as previsões, claro está que não ha cousas ou factos que sejam em absoluto confidenciaes, ou cuja revelação seja inseparavel de uma eventualidade de prejuizo e deva, por isso, sugeitar o revelador á sancção do art. 192 do Cod. Penal.

Assim, desde que a parte interessada entende que a quebra do sigillo não é, ou deixou de ser, nociva, e por isso a autorisa, ou até a reclama, dissipa-se o caracter sigillar e a consequente necessidade de resguardal-o, mediante pena criminal contra o revelador. Só havia segredo-uma cousa que a ninguem convinha fosse revelacla-porque as circumstancias determinavam tal conveniencia em relação a certos e determinados individuos, a quem a revelação poderia 
impor prejuizos de qualquer naturesa; mas eis que são mudadas as circumstancias e com ellas mudadas as conveniencias, fica sem razão de ser, e, portanto, inexistente, a necessidade do sigillo imposta e sanccionada pelo art. 192 do Cod. Penal.

O juiz da mutação das circumstancias, e consequente mutação das conveniencias, não póde ser a sociedade ou a justiça publica, representada por seus oryãos; o juiz é, necessariamente, o proprio individuo, porque só elle póde bem aprehender e bem regular e apreciar todos os fios que constituem a trama de sua vida individual e social.

Por isso Jeremias Bentham, como sagaz observador que era, escreveu o seguinte: «Nada mais natu«ral que presumir-se não existir mal, ou que elle foi "perfeitamente compensado, quando houve consenti«mento. Assim, admittimos a regra geral dos juris«consultos -o consentimento derime a injuria. Esta «regra funda-se em duas proposições bem simples: «uma, que cada qual é o melhor juiz do seu proprio «interesse; a outra que um homem jamais consentiria «no que acreditasse ser-lhe nocivo.»

Mas si não é à sociedade, e sim o individuo, o juiz apto para apreciar o prejuizo resultante das revelações, e si esse prejuizo é a causa determinante do sigillo, é bem visto que o caracter confidencial dos factos não é absoluto, objectivo e independente da apreciação e vontade dos interessados, como pretende o nosso contradictor.

Ainda mais. Com a estatuida incriminação, o fim do legislador foi amparar efficazmente a confiança que muitas pessoas são forçadas a depositar nos profissionaes a cujos serviços carecem recorrer, porque

(3) Auvres de J. Bentham, Bruxelles, I84o, Tom. I, pag. I3I. 
sem essa confiança, garantida pela sancção penal, além da obrigação civil de indemnisar o damno causado, muitos seriam induzidos a sacrificar altos e respeitaveis interesses, afim de poderem obviar as consequencias funestas de perversa ou leviana indiscreção. Sendo este o motivo-da lei, claro está que a supradita disposição penal não se póde entender applicavel ao caso em que a acquiescencia do interessado exclue de vez a possibilidade do abuso de confiança e o consequente alarma social.

Desde que sempre assentam sobre a base da confiança a escolha do profissional e a invocação de seus serviços, a revelação 'dos factos conhecidos no exercicio ou em rasão da profissão é sempre um abuso de confiança, embora muitas vezes o conhecimento dos mesmos factos não resulte de uma confidencia directa e pessoalmente feita ao profissional e seja indirectamente adquirido no exercicio ou em rasão da profissão. Assim sendo, o abuso da confiança e o alarma sucial, que elle provioca, são o motivo da lei, o qual, evidentemente, não prevalece na hypothese em questão; pelo que é de presumir que o legislador não tivesse querido extender até essa figurada hypothese o imperio da regra legislativa.

E a regra legislativa não é outra cousa mais que um producto da rasão social externado pela.vontade do legislador: "Non enim lex est quod scriptum est, sed quod legislator voluit, quod judicio suo probavit et recepit. ( $L$. de quibus, ff. de legib.)

Assim, pois, não prevalecem os fundamentos com que o nosso contradictor pretende excluir da mente do legislador criminal patrio a restricção por nós sustentada. $O$ douto critico, porém, que assim rejeita a nossa interpretação restrictiva, tão directamente apoiada 
no motivo da lei, não está tão distanciado de nós como parece.

Com effeito, empregando a phraseologia nova com que Ferri, Garofalo e sua escola sóem vestir idéas velhas-o que Aramburú denominou prurido technologico o nosso douto contradictor escreveu o seguinte: «nào, ha contestar que, toda a vez que essa revelação se verificar em condições taes, que deixe de constituir a manifestação dum caracter carecente da reserva e discreção necessarias ao desempenho da profissão medica, e, consequentemente, um indicio de temibilidade social, da parte de seu autor, cessa, tambem, por completo, a rasão do emprego de medidas repressivas contra este.» $\mathrm{E}$ mais adiante escreve ainda o critico: «a autorisação do dono ou senhor do segredo-autorisação em face da qual cessa o perigo social do desvendamento - não se deve considerar mais do que a condição ou elemento meramente determinativo da impunibilidade do medico autor do mesmo desvendamento, cuja inincriminação outra base não tem senão a propria ausencia daquelle perigo social.»

Si, para nós, a pena não é simplesmente uma reacção defensiva do organismo social lesado, consoante a doutrina de Ferri, todavia o perigo social é sempre um elemento essencial do systema de repressões penaes. Como o douto critico, não comprehendemos incriminação de um facto sem que este possa, de qualquer modo, acarretar perigo social; e de accordo com este pensar foi que demos ao art. I 92 do Cod. Penal a interpretação restricta rejeitada pelo nosso contradictor. Não plidemos então, nem podemus ainda, conceber que um facto incapaz de produzir perigo social, ou o alarma provocado por tal perigo, pudesse

(4) Rev: Medico Legal, n. 4-1896, pag. 250 e 253. 
ter sido submettido pela vontade do legislador a uma repressão penal.

Ora, o nosso contradictor, que tambem reputa inseparaveis a incriminação e o perigo social no dominio da doutrina e da sciencia, attribue ao legislador criminal patrio o desconchavo de haver divorciado, nas taboas da lei, as duas referidas idéas. E' manifesto illogismo, porque ninguem póde entender a lei attribuindo absurdos an legislador.

Muito ao envez disso, a hermeneutica, pela voz autorisadissima do já citado Mailher de Chassat, tratando de expor as regras da interpretação restrictiva, ensina que «é argumento proprio para se discernir o motivo da lei, e para autorisar a restricção della, o raciocinio que levaria ao absurdo, si a lei não fosse restringida.» (5) Interpretatio illa szimenda, qua absurdum evitetur.

O nosso douto contradictor lembra que o consentimento do offendido não derime nem exclue a intenção criminosa, menos nos casos em que a lei só a elle permitte acção criminal (art. 26, letra C do Cod. Penal), e pondéra mais que o crime definido no art. I 92 do Cod. não está incluiclo entre as excepções ou limitações da acção publica estatuidas no art. 407 do mesmó Codigo. Dahi pretende o critico inferir que, ante a lei penal brasileira, é punivel a revelação dos factos confidenciaes depois da autorisação prestada pelas partes interessadas.

Sem querer deslisar-me da cortesia que por tantos titulos devo ao meu contradictor, peço-lhe venia para dizer que este seu argumento tende a resolver a controversia por um verdadeiro circulo vicioso.

(5) M. DE ChaSSa'T. op. cit. $\S 12 I$, pag. I8\%. 
Com effeito, o que está em questão é si a revelação feita nas condiç̃os expostas constitue o crime definido pelo art. I92 do Codigo; e o illustrado critico, invocando o disposto nos arts. 26 e 407 do Cod., já presuppoe a existencia lo crime, porque só havendo crime é que podem existir a intenção criminosa e a acção criminal a que se referem as invoćadas disposiçoes. A figura juridica do crime está na revelação feita com abuso de confiança, porque este offende $o$ interesse legitimo dos individuos e offende tambem a collectividade social, pelo alarma que produz, incutindo em todos o natural receio de não poderem garantidamente recorrer aos serviços de profissionaes indiscretos. Portanto, rompido o sigillo por quem tinha interesse em resguardal-o e pelo unico juiz competente para aquilatar esse interesse e confrontal-o com outros interesses seus, porventura inconciliaveis com elle, desapparece o abuso de confiança, è, com a ausencia deste, dissipa-se o alarma social; isto é, a inexistencia dos elementos constitutivos do delicto impossibilita a existencia delle na tela juridica.

E tal foi a conclusão a que chegámos, não obstante conhecermos em contrario a doutrina de Faustin e Hélie e a de alguns julgados dos tribunaes francezes invocados e citados por Ch. Vibert ( I6), os quaes são agora novamente adduzidos como argumento pelo nosso illustrado contradictor. Mas, para a valia desta especie de argumento, seria indispensavel fossem rebatidos-e não o foram-os fundamentos que adduzimos para não aceitar a doutrina propugnada pelo nosso contradictor á sombra das referidas autoridades

Os dous illustres criminalistas francezes limitaram-se a perfilhar e a reproduzir quasi textualmente 696.

(6) Charles Vibert. Précis de Méd. Lég. Parzs, I893, pag. 695 
a doutrina da Côrte de Montpellier, que é a seguinte: «a obrigação do segredo subsiste ainda no caso em «que aquelle a quem os factos concernem e que os «confiou peça a revelação; porque a obrigação pres"cripta pelo art. 378 é estabelecida no interesse geral, «e só é por este meio (ce n'est qu'á ce prix) que «podem gozar da confiança e da consideração neces«sarias, profissões cujo exercicio importa á sociedade «inteira.»

O interesse publico amparado pelo art. 192 do Cod. Penal consiste, dissemos nós, (8) «em resguar«dar contra os abusos a confiança obrigada por parte «daquelles que necessitam recorrer a certa ordem de «profissionaes». Carrara, para enumerar este crime na classe dns crimes contra os direitos individuaes, o que, aliás, tambem fez o nosso Codigo, diz que a lei protege com uma pena a confiança (la fiducia da un tradimento), para garantir o livre recurso ás profissões que presuppoem a mesma confiança (professioni fiduciosi). (9)

Assim sendo, o que é incontestavel e o nosso contradictor não o contestou, é manifesto que o «interesse geral», a que se referem os supracitados escriptores e arestos francezes, desapparece no caso sugeito, desde que a ausencia do abuso de confiança exclue o alarma social, que o douto critico, para falar como Garofalo, denominou a «temibilidade social.»

Si para tanto assistisse-nos autoridade, remetteriamos o nosso douto contradictor á prudentissima reserva com que o grande Bacon, nos seus Aphorismos, aconselhava fossem invocados e acceitos os julgados e arestos, principalmente quando se não póde

(7) Ch. Vibert. op. cit. loc. cit.

(8) Rev. da Fac. do Dir. de S. Paulo, z'ol. III, pag. 29.

(9) Carrara. Programma. \& I6 4 I. 
conhecer todas as circumstancias das causas e todas as influições e correntes que, em determinado tempo, convergem sobre os juizos e sobre os julgamentos dos homens. Em França como aqui, hontem como hoje e como no tempo do velho Ulpiano ou de Bacon, ha julgados que mais prejudicam do que ensinam- «magis nocent quam docent»; alguns conhecemos nós verdadeiramente assombrosos e que seriam de todo alarmantes, si não nos assistisse o direito de contrapor-lhes, em defeza, como parapeito ou baluarte, o velho brocardo juridico: Legibus, non exemplss, judicandum est.

Para fechar com chave de ouro este nosso despretencioso trabalho, vamos trasladar mais um trecho devido á penna do douto critico: «O consentimento do interessado só ROUBA Á REVELAÇÃO DO SEGREDO O CARACTER DELICTUOSO e exime da respectiva pena o revelador, quando precede a essa revelação, e jamais quando «lhe é posterior» (Io).

Je plenissimo accordo. O consentimento posterior á revelação não derimiria a consummação do delicto, já effectuada pelo abuso de confiança. O acto equivaleria a perdão do offendido, o qual só extıngue a acção penal nos crimes pelos quaes se não póde proceder sinão por queixa da parte (art. 77 do Cod.), e entre estes não se conta o crime do art 192 do Cod., por não ter sido incluido nas excepções do art. $407 \S 2 .^{\circ}$ do mesmo Cod., o que aliás no dominio do jus constituendum não nos parece acertado.

$O$ trecho supra transcripto, que exprime a opinião do nosso contradictor ante a sciencia e o direito por constituir, bem está mostrando quão tenue é a linha de separação que nos divide, desde que

(xo) Rev. Medico Legal $4{ }^{\circ}-1896$, pag. 256 nata 31 . 
ambos, á luz dos principios e da critica juridica, somos accordes em proclamar que «o consentimento do interessado rouba á revelação do segredo o caracter delictuoso».

A divergencia, ao que parece, está sómente em que o nosso douto contradictor acredita que aquella verdade scientifica não foi acceita pelo legislador patrio e não está virtualmente contida nos termos do art. 192 do Cod. Penal.

Mas porque pretende o critico emprestar á nossa lei criminal um conceito que elle entende, scientificamente falando, ser um absurdo? Sómente porque o legislador brasileiro deixou de copiar servilmente os termos do Codigo do Imperio Allemão? O motivu não nos parece sufficiente, desde que uma idéa póde ser tracluzida por differentes vocabulos, contendo estes maior ou menor concisão, sempre sem prejuizo da claresa, que é, no dizer de Michelet, a probidade das linguas e denuncía a probidade do legislador, assim como a concisão denuncía o seu saber.

Ao envez do critico, pensamos que o legislador criminal brasileiro, ao menos na redacção do art. I 92 do Cod. Penal, não se divorciou dos dictames da sciencia, e mais concisa e mais elegantemente substanciou alli a mesma restricção acceita pela lei criminal alleman.

E' o que pensamos ter demonstrado.

Ha uma phrase feliz de Royer Collard que o interprete póde bastantes vezes fazer sua e que pedimos licença para adoptar agora e contrapor ao critico: * Cela ne peut pas être, donc cela n'est pas».

S. Paulo, 3 I de Agosto de I 896.

Aureliano de Sonza e Oliveiza Continho. 